\title{
Correction: Reduced expression of AMPK-ß1 during tumor progression enhances the oncogenic capacity of advanced ovarian cancer
}

\author{
Cuilan Li ${ }^{1,3}$, Vincent WS Liư', Pui Man Chiu', Kwok-Ming Yao², Hextan YS Ngan ${ }^{1 *}$ and David W Chan ${ }^{1 *}$
}

\section{Correction}

After publication of this article [1] the authors noticed an error in Figure 5A, B and D (Figure 1 here). In Figure $5 \mathrm{~A}$ (Figure 1 here), the same image from AMPK- $\beta 1$ was erroneously used for pAMPK $\alpha$ of A2780cp- $\beta 1$ panel. The correct image for pAMPK $\alpha$ is now provided. In Figure 5B and D (Figure 1 here), the panel of OV2008-sh $\beta 1$ used two different sets of b-actin. The b-actin in Figure $5 \mathrm{~B}$ (Figure 1 here) is now used for the whole panel of OV2008-sh $\beta 1$ in Figure 5B and D (Figure 1 here). These errors were unintentionally made during figure preparation and do not in any way alter the results or conclusions of this study. The authors apologize that these errors were not detected earlier.

\footnotetext{
* Correspondence: hysngan@hku.hk; dwchan@hku.hk

'Department of Obstetrics \& Gynecology, The University of Hong Kong, 6th Floor, Professorial Block, Queen Mary Hospital, Pokfulam, Hong Kong, SAR, People's Republic of China

Full list of author information is available at the end of the article
} 


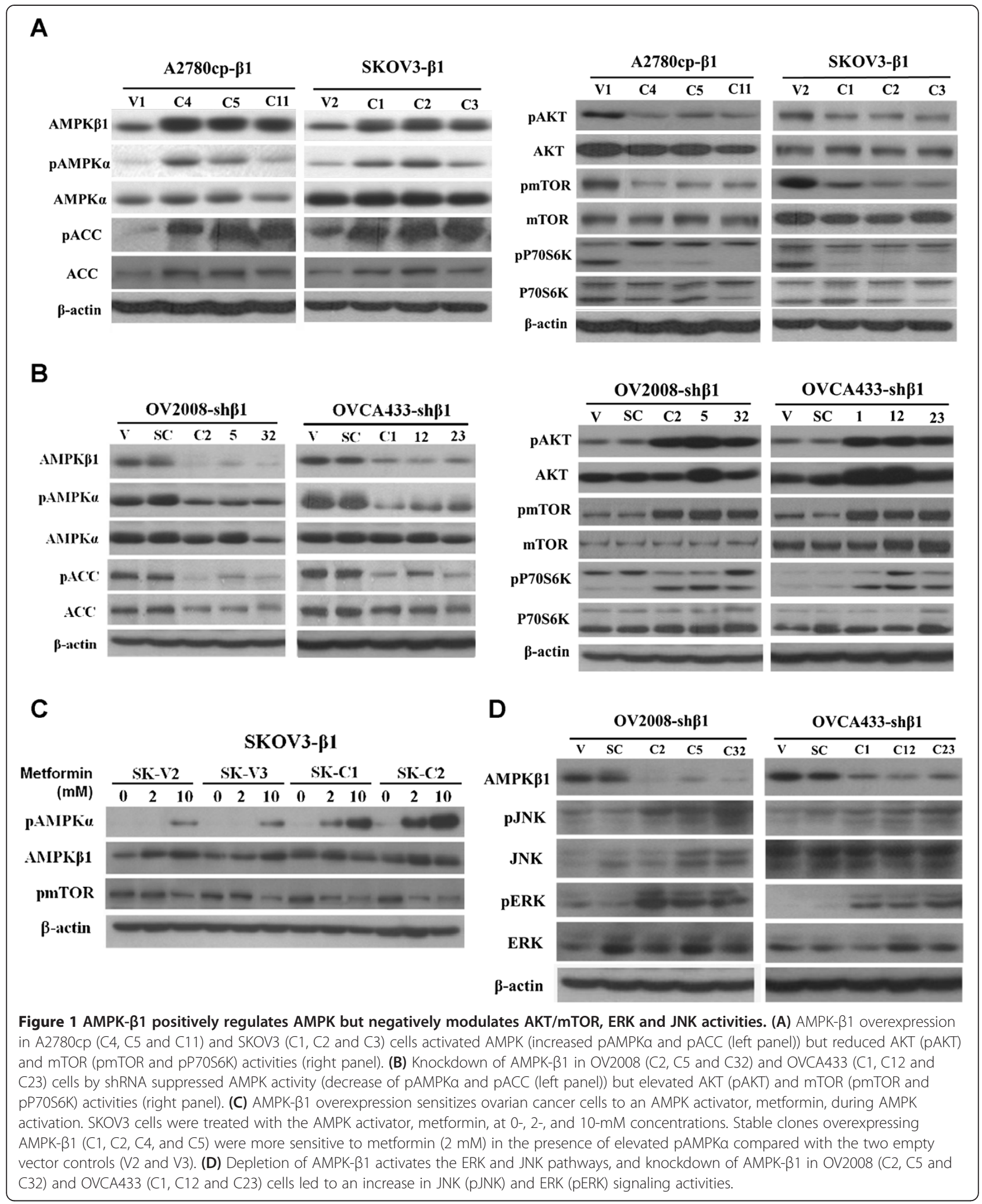




\section{Author details}

${ }^{1}$ Department of Obstetrics \& Gynecology, The University of Hong Kong, 6th Floor, Professorial Block, Queen Mary Hospital, Pokfulam, Hong Kong, SAR, People's Republic of China. ${ }^{2}$ Department of Biochemistry, LKS Faculty of Medicine, The University of Hong Kong, Hong Kong, SAR, People's Republic of China. ${ }^{3}$ Department of Obstetrics \& Gynecology of The Third Affiliated Hospital of Guangzhou Medical University \& Key Laboratory for Major

Obstetric Diseases of Guangdong Province, Guangzhou, People's Republic of China.

Received: 30 June 2014 Accepted: 30 June 2014

Published: 4 August 2014

\section{References}

1. Li C, Liu WWS, Chiu PM, Yao KM, Ngam HYS, Chan DW: Reduced expression of AMPK- $ß 1$ during tumor progression enhances the oncogenic capacity of advanced ovarian cancer. Mol Cancer 2014, 13:49.

doi:10.1186/1476-4598-13-161

Cite this article as: Li et al:: Correction: Reduced expression of AMPK-B1 during tumor progression enhances the oncogenic capacity of advanced ovarian cancer. Molecular Cancer 2014 13:161.

\section{Submit your next manuscript to BioMed Central and take full advantage of:}

- Convenient online submission

- Thorough peer review

- No space constraints or color figure charges

- Immediate publication on acceptance

- Inclusion in PubMed, CAS, Scopus and Google Scholar

- Research which is freely available for redistribution 